\title{
CARTOGRAFIAS DISSIDENTES: CORPO, SEXO, GÊNERO E DISCURSO COMO DISPOSITIVOS DE MAPEAMENTOS DE RESISTÊNCIAS E CATEGORIAS DE ANÁLISE SOCIAIS URBANAS.
}

\section{DISSIDENT CARTOGRAPHIES: BODY, SEX, GENDER AND DISCOURSE AS DEVICES FOR MAPPING RESISTANCE AND URBAN SOCIAL ANALYSIS CATEGORIES.}

PAGNAN, REDSON

DOUTORANDO EM ARQUITETURA E URBANISMO NA UNIVERSIDADE PRESBITERIANA MACKENZIE (BOLSISTA CAPES PROEX).

MESTRE EM LINGUÍSTICA PELA UNIVERSIDADE DE FRANCA (BOLSISTA CAPES UNIFRAN/2019) REDSON.PAGNAN@GMAIL.COM

ORCID ID: HTTP://ORCID.ORG/0000-0002-1912-6661

\section{RESUMO}

Neste artigo discuto as inter-relações estabelecidas entre gênero, sexualidade e espaço urbano. O interesse maior recaí sobre os modos como podemos ler as categorias de corpo, sexo e gênero como dispositivos de mapeamentos de resistências que possam auxiliar em análises e descrições do 'sujeito-queer' em nossa sociedade, nas diversas análises possíveis. As identidades dissidentes ou 'desviantes', ocupam e ressignificam o espaço urbano de formas diferentes, dotando-os de novos significados e, assim, subvertendo seu valor inicial. Desse modo, trago como objeto de leitura a plataforma colaborativa 'Queering the Map' demonstrando como o ciberespaço se insere como um dispositivo de cartografias contemporâneas. Na análise faço gestos de leitura e interpretação entendendo a linguagem como performance a partir dos atos de fala e, também, com outras reflexões vindas da teoria da arquitetura e dos estudos urbanos, além das teorias Queer que colaboram com leitura de práticas não-binárias. 
Palavras-chave: análise do discurso; gênero e sexualidade; cartografias dissidentes; queer; ciberespaço.

\section{ABSTRACT:}

Tionships established between gender, sexuality and urban space. The greatest interest falls on the ways in which we can read the categories of body, sex and gender as devices for mapping resistances that can assist in analyzes and descriptions of the 'subject-queer' in our society, in the various possible analyzes. Dissident or 'deviant' identities occupy and resignify urban space in different ways, endowing them with new meanings and, thus, subverting their initial value. In this way, I bring as a reading object the collaborative platform 'Queering the Map' demonstrating how cyberspace is inserted as a device of contemporary cartography. In the analysis, I make gestures of reading and interpretation, understanding language as a performance based on speech acts and, also, with other reflections coming from the theory of architecture and urban studies, in addition to Queer theories that collaborate with the reading of non-binary practices.

Keywords: discourse analysis; gender and sexuality; dissident cartographies; queer; cyberspace.

"De todos os assuntos de que participamos com maior ou menor interesse, a busca às cegas por uma nova maneira de viver é a única questão que continua sendo apaixonante."

Guy Debord ${ }^{1}$

\section{INTRODUÇÃO - NOTAS PARA UMA LEITURA DIFERENCIADA}

Esteartigo se insere como um primeirogesto de leitura e interpretação a respeito da minha pesquisa de doutorado sobre como pensar as interrelações de gênero, sexualidade e espaço urbano. Historicamente, as cidades têm sido estruturadas de uma forma que conservam a homogeneização e elitização dos espaços, isto é, a cidade pouco acolhe as diferenças, fazendo com que as minorias sociais estabeleçam sempre

1 Guy Debord. "Introducción a la crítica de la geografia urbana", em Libero Andreotti e Xavier Costa (orgs.), Teoria de la deriva y otros textos situacionistas sobre la ciudad. Barcelona, Actar, 1996, p. 18. 
uma relação de trânsito com o território (cf. CÓRTES, 2008). Oferecer a benevolência como sustentação da civilização em um mundo repleto de violência, faz parte do universo da Arquitetura, mas muitos arquitetos e urbanistas têm esquecido da dimensão e da diversidade humana existente no tecido urbano (cf. GEHL, 2015). Os livros de arquitetura e urbanismo, o trabalho prático dos arquitetos e urbanistas, assim como o ensino da disciplina reforçam esses ideais.

Há mais de cinquenta anos, Jane Jacobs ${ }^{2}$ vem nos alertando sobre como o pensamento racionalista da ideologia modernista que distingue usos espaciais da cidade e celebra edifícios (e sujeitos) autônomos, colocariam um fim ao espaço urbano e à vida nas cidades, resultando em espaços esvaziados de pessoas, de diversidade. De fato, o rumo dos acontecimentos históricos, sociais e culturais nas cidades, não só reduziram as oportunidades para os cidadãos, como também os inibiu, deixando as funções e usos do espaço das cidades extremamente limitadas. As cidades absorveram as características racionalistas do Modernismo e passaram a operar em função da economia, onde progressivamente, a tradicional função da cidade como local de encontro foi sendo reduzida, ameaçada e/ou talhada (cf. GEHL, 2015).

A cidade espacialmente e ideologicamente excludente, aliada à falta de políticas públicas inclusivas e funcionais, acaba tornando-se uma materialidade geradora de respostas (voluntárias ou não) sobre as ações contidas em si mesma. Estas respostas podem ser lidas como enunciados das diferentes camadas sociais. Assim, esses habitantes tornam-se coautores da cidade, colaborando nas criações espaciais e também na fomentação de um discurso sobre a cidade, agindo ativamente não só com o corpo, mas também com as palavras. Desse modo, ser coautor da cidade é compartilhar da criação dos diferentes espaços e de situações que se desenvolvem no espaço urbano, de modo material ou imaterial. Os coautores são aqui entendidos por indivíduos ou grupos (sujeitos, arquitetos, coletivos, ativistas, ONG's, etc.) que de alguma forma intervém na dinâmica da cidade, da cotidiana vida urbana.

Portanto, trabalhando com essa ideia de aproximação entre 'corpo', 'cidade' e 'discurso', inicialmente faço algumas observações sobre como a teoria da arquitetura, aos poucos, foi incluindo em seu 'discurso' novas

2 Jane Butzner Jacobs (1916 - 2006) foi uma escritora e ativista política do Canadá, nascida nos Estados Unidos. Sua obra mais conhecida é Morte e Vida de Grandes Cidades (The Death and Life of Great American Cities, 1961) onde critica duramente as práticas de renovação do espaço público da década de 1950 nos Estados Unidos. 
práticas, ideias e sujeitos, então, esboço uma breve aproximação com a teoria queer, que me permite leituras e interpretações diferenciadas dos padrões binários e normativos existentes. Na sequência, comento alguns conceitos relacionados ao corpo, sexualidade e identidade, sempre que possível relacionando-os com o espaço urbano. Em seguida, trago uma breve observação sobre a linguagem como performance, consideração os atos de fala. Na sequência apresento o projeto colaborativo "Queering the Map" como um dispositivo cartográfico, isto é, uma ferramenta que permite leituras e interpretações da cidade a partir dos discursos e dos modos de apropriação urbana.

Assim, o que me interessa neste trabalho é discutir a função social da arquitetura e urbanismo e o modo como os indivíduos/ grupos subvertem - com seus corpos, sua existência, suas palavras - o significado dos espaços urbanos e até mesmo o significado de suas próprias existências. $\mathrm{E}$, ainda, demonstrar que as categorias de gênero, sexo, raça e classe são importantes marcadores sociais que devem ser considerados para as diversas análises sociais urbanas, especificamente nesta discussão, entendendo como uma plataforma virtual (o Queering the Map) pode ser relevante nesse processo.

\section{ALGUMAS APROXIMAÇÕES ENTRE A ARQUITETURA E O ‘QUEER’: O ES- PAÇO, O CORPO E O DISCURSO}

A teoria da arquitetura é um 'discurso' sobre a prática da profissão e também sobre a produção da disciplina (cf. NESBITT, 2006). O discurso, para Dominique Maingeneau (2008) é prática discursiva, já que está para além do texto, integrando todos os planos e não somente a intertextualidade. Isto é, agimos no mundo e fazemos coisas com nossos discursos. A produção do discurso está ligada ao estatuto de uma certa comunidade de enunciadores, que conferem significado aquilo que é 'dito' ou 'feito'. A produção da arquitetura está ligada a uma certa comunidade de arquitetos que (enunciam) conferem sentido aquilo que é construído. Em ambos os casos, os enunciadores definem seu 'status' e seu modo de enunciação, inscrevendo-se em uma certa posição social (cf. MAINGUENEAU, 2008).

Ao longo da história é possível identificar no 'discurso arquitetônico' certos problemas que necessitam de soluções relacionadas ao espaço físico e outros que estão voltados para os esclarecimentos conceituais. As questões físicas são resolvidas pela técnica, enquanto as conceituais 
são abordadas a partir da filosofia. Dentre os inúmeros temas possíveis estão as origens da arquitetura, sua forma e função, sua relação com a paisagem, com a cultura, com outras artes e os seus significados e, mais recentemente, a sua relação com os sujeitos, no sentido de considerar a diversidade de experiências e vivências com o espaço urbano e não somente um 'sujeito universal' como interlocutor dos projetos.

A ampla abordagem de assuntos acontece porque a Arquitetura lida com as inúmeras atividades que envolvem todas as esferas da vida humana social. Os modos de organização da sociedade e de circulação, os modos de trabalho e de lazer, as nossas relações amorosas, afetivas e sexuais. Ou seja, tudo que envolve o comportamento humano e a vida social cotidiana está entrelaçado com as preocupações da teoria da arquitetura. Estes inúmeros conflitos materializam-se no tecido urbano, visto que a cidade é a sociedade global projetada no solo (cf. LEFEBVRE, 2001). Daí vem a importância fundamental de entender que as intervenções urbanas ${ }^{3}$ transformam os modos de vida cotidianos, uma vez que o espaço urbano não é homogêneo, nem apolítico e tampouco concebido sem si para si mesmo (cf. CÓRTES, 2008). Pelo contrário, o espaço nunca permanece estático, muito menos o discurso, porque ambos são produtos da história, fazem parte de um modo de inscrição social e são 'lugares' de encontro das ideias e dos interesses culturais, materiais e financeiros. Os diferentes indivíduos e grupos que habitam o território urbano sempre buscaram se relacionar com o mundo e, é através da intencionalidade pensada que o sujeito se descobre ligado ao objeto (cf. BOUTINET, 1990). Isto é, ligado a cidade, ao espaço urbano, à algum lugar.

Nesse contexto, a teoria crítica da arquitetura avalia o mundo e as suas relações com a sociedade a que serve (cf. NESBITT, 2006). É naturalmente polêmica e questionadora, além de muitas vezes conter orientações éticas e políticas explícitas, já que tem por intenção estimular mudanças. Assim, pode afiliarse ideologicamente à outras correntes de pensamento, como o marxismo ou o feminismo.

Não por acaso, desde a década de 1960, a teoria da arquitetura vem se caracterizando por sua interdisciplinaridade e pela abertura a outros discursos. De um modo geral, alinhando-se ao pós-modernismo

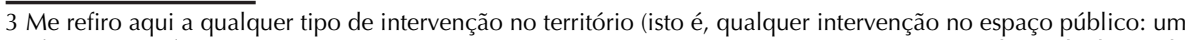
grafite, uma performance, uma apropriação temporária etc.) e não somente uma intervenção urbana de demanda pública realizada por algum órgão específico. 
como modo de investigação de alguns temas e estruturando-se pela proliferação de paradigmas teóricos e de classificações ideológicas para fomentar suas discussões, quase sempre, pós-estruturalistas.

Foi também a partir da década de 60 (e dos primeiros anos dos 1970) que o território urbano ficou marcado pelas lutas das mulheres, dos gays e dos negros contra os preconceitos que sofreram. Pautados por essas experiências de resistência, muitos dos movimentos sociais que surgiram a partir de então - principalmente o feminista - fizeram com que as categorias de gênero e sexo se tornassem tão importantes para uma análise social, quanto às categorias de classe e raça (cf. SPARGO, 2017). Nessa efervescência política de contestações sobre o poder, identidade, raça e gênero, surgiram alguns coletivos de arquitetos e artistas que passaram a tencionar esses aspectos não examinados, não abordados ou esquecidos no campo da arquitetura e urbanismo, como por exemplo os Situacionistas ${ }^{4}$ e o Team $10^{5}$. Movimento que se repete até os dias de hoje.

As reflexões que surgiram desse momento foram pertinentes em relação aos novos modos de ocupação e significação das cidades, elas foram postas, principalmente, pela Internacional Situacionista, grupo que surge a partir da fusão de três movimentos de vanguarda ${ }^{6}$. Com o olhar voltado para a produção artística e também para a construção de uma nova sociabilidade, criticam a vida cotidiana monótona e indicam a criação de situações (daí o nome do grupo) e de novas formas de utilização dos espaços urbanos. Não só os Situacionistas, mas também artistas como Gordon Matta-Clark ${ }^{7}$ e Vito Acconci ${ }^{8}$ apoiaram-se em filósofos como Henri Lefebvre, Martin Heidegger e Michel Foucault, que escreveram sobre valorizar a vida e o ser cotidiano nas sociedades urbanas ocidentais, apontando pra novos olhares que não o racional.

Dessa forma, nesse momento as abordagens e inter-relações acontecem a partir das aproximações com as questões filosóficas, sociológicas, marxistas, linguísticas e feministas, isto é, a teoria da

\footnotetext{
4 Movimento internacional de cunho político e artístico. O movimento Internacional Situacionista foi ativo no final da década de 1960 e aspirava por grandes transformações políticas e sociais articulando conceitos de arte, urbanismo e vida social. A primeira IS foi desfeita após o ano de 1972.

5 Team 10 foi um grupo de arquitetos que se opunham às doutrinas Modernistas.

6 Os grupos que dão origem a Internacional Situacionista são: Internacional Letrista, Movimento por uma Bauhaus imaginista e Comitê Psicogeográfico de Londres.

7 Gordon Matta-Clark (1943 - 1978) foi um artista norte-americano, famosos pelo "Building Cuts" uma série de trabalhos em edifícios abandonados, onde em uma atitude pós-modernista, ele removia partes do piso, teto e paredes dos andares e olhava para dentro das estruturas.

8 Vito Acconci (1940 - 2017) foi um arquiteto norte-americano que realizou inúmeras performances opondo-se ao caráter comercial da arte, desenvolvendo manifestações efêmeras e ligadas as relações entre o homem, o sexo e o desejo.
} 
arquitetura passa também a considerar abordagens mais humanistas nas suas práticas, mesmo que na prática da profissão em si esse olhar ainda seja negligenciado. A partir dessas ideias e dessa 'abertura', podemos dizer, mais 'humanistas', é que se desenvolveram trabalhos que descrevem como o sujeito vai buscar reconhecimento pelas práticas sociais com as quais conquistará visibilidade e 'status' social perante um grupo. Isto é, o direito à cidade (cf. LEFEBVRE, 2001).

Desse modo, a arquitetura como uma prática social que expressa a cultura de uma época e de um povo, é em si mesma um dispositivo de poder (cf. FOUCAULT, 1987). Um dispositivo de subjetivação que concentra em si a categoria de gênero que é uma experiência coletiva ${ }^{9}$. Isto é, a arquitetura cria os lugares onde se desenrolam nossa existência. Ela se insere como um dispositivo de poder que estabelece as ordens, fronteiras e os modos de como vemos e vivemos o mundo ao nosso redor, o que Foucault chama de 'arquiteturas de aprisionamento' - a prisão, o hospital, a escola, o quartel, a igreja, a casa, etc. - ao fazer essa observação, Foucault além de fornecer um dado importante para as análises de corpos dissidentes, insere um pensamento de como as instituições produzem sujeitos culturais e também produzem as identidades e sexualidades através da opressão, da exclusão ou da normalização (cf. PRECIADO, 2017).

Nesse sentido, podemos dizer que o homem sempre buscou relacionar-se com as coisas ao seu redor através do corpo, que é a matéria. Na linguagem o corpo torna-se matéria e por ela é significado. Na cidade, o corpo é matéria que se transforma e que é transformado pela cristalização dos seus atos (cf. BUTLER, 2017). Assim, "pensar o corpo, hoje, é pensar suas vivências (performances), numa visão que o contemple como um dos elementos constitutivos do amplo universo semiótico, em que se produzem as subjetividades" (VILLAÇA, 2009, p. 35). Mais que um organismo físico e/ou material, o corpo é uma materialidade carregada de códigos dos quais usamos para nos situar no mundo e tais signos nos ajudam a entender quem somos. A configuração do nosso corpo influência de forma mais que evidente nossa existência social e cultural (cf. CORTÉS, 2008).

Assim, no mundo em que vivemos, no qual a aparência

9 É uma experiência individual, vivida coletivamente, faz parte da vida cotidiana. Todas as pessoas buscam encontrar o seu, mesmo que inconscientemente e todos fazem isso singularmente, mas ao mesmo tempo. 
e a imagem são signos de valor, o corpo não apenas transmite mensagens à sociedade, mas ele também passa a ser o conteúdo dessas mensagens (cf. CORTÉS, 2008). Portanto o corpo, o sexo, o gênero (e a raça) são categorias inter-relacionadas que funcionam simultaneamente, como um nó borromeu, transmitindo informações em forma de enunciados, sejam eles verbais ou nãoverbais. E, assim, insere-se como importantes categorias de análises que envolvem o sujeito, já que são os sujeitos que carregam esses marcadores sociais em si mesmos.

Ao apropriar-se do espaço o corpo gera a vida, possibilita a troca e a interação. Portanto, ele é mais do que aquilo que observamos externamente. É um símbolo pessoal e social de identidade (cf. CÓRTES, 2008). E, é pelo corpo que damos sentido à nós mesmos, ou seja, é um veículo metafórico de significados. Na sociedade ocidental, o nosso corpo configura nossa existência social e cultural. "A imagem do corpo é o efeito, o resultado, a construção que se produz por meio da subjetivação das estruturas que antecedem nossa entrada no mundo" (cf. CORTÉS, 2008, p. 125). Isto é, o corpo é matéria, resultado da cristalização das nossas ações no dia-a-dia (cf. BUTLER, 2017). Por isso, somos sujeitos socialmente e historicamente inscritos na história. Assim, o corpo também se insere como um importante dispositivo de análise cartográfica. É no corpo que ocorre o primeiro lugar da existência social, esse lugar social se transforma na experiência vivida no território e, assim, o território passa a ser uma territorialidade.

Desse modo, o corpo e o lugar configuram a existência. A partir desse olhar, ao longo da história construiu-se um ideal de corpo atrelado ao sexo masculino e muitas vezes significado por palavras como ação, ativo, saudável, quente (cf. SENNETT, 2016). Como escreve Aaron Betsky (1995, p. 22) "o imaginário do corpo masculino está em qualquer lugar, da construção fálica dos arranha-céus às construções 'musculares' de nossos órgãos públicos. Os papeis do Homem e seu poder se fazem reais por meio da arquitetura'. O que protege o homem nesse sentido é o ideal ativo que conecta o corpo do homem em uma espacialidade de poder e moralidade social, fazendo com que esse homem tenha medo da passividade, o que implicaria em perda de privilégios (cf. CÓRTES, 2008).

Dessa forma, não só o corpo, mas também o gênero e o sexo 
passam a ser importantes dispositivos de análise urbana e social, pois inserem marcadores de diferenças, ou seja, expõe que esses sujeitos experimentam o espaço de modos diferentes. Portanto, se o homem ocupa todo o espaço e se o espaço representa e de certa forma protege e ratifica o ideal masculino, o corpo das mulheres e dos gays (entre outras minorias) estiveram ausentes, foram silenciados e/ou negados durante muitos anos. Assim, o espaço doméstico - ou privado - foi, durante muito tempo o único lugar possível para esses corpos, onde eles podiam se expressar com 'certa liberdade', pois a casa torna-se acolhedora ao mesmo tempo que serve de prisão, ou seja, tem um caráter duplo.

Nesse sentido, paras os corpos dissidentes, o simples ato de circular por um espaço público já se torna uma subversão desse espaço, tendo em mente que estes corpos sempre foram negados no espaço público. Assim, a teoria da arquitetura aproximase filosoficamente com base no método conhecido como fenomenologia (cf. NESBITT, 2006) para discutir atitudes pósmodernas com mais atenção ao modo de fazer as coisas, à cidade, o lugar, à paisagem, que muitas vezes foram deixadas de lado.

Desse modo, a reflexão fenomenológica da arquitetura passou a preparar as discussões sobre os assuntos mais contemporâneos e ligados ao modo como uma obra de arquitetura - assim como uma obra de arte - toca, provoca e faz um sujeito se sentir (cf. NESBITT, 2006). Portanto, podemos dizer brevemente que é a partir das críticas em relação as ações de caráter modernista, isto é, que olhar para a cidade de modo muito racional e funcionalista, que a arquitetura (por força dos arquitetos, dos coletivos, dos sujeitossociais) se abriu para um novo entendimento do modo como agimos na cidade, nos espaços urbanos e quais reflexões podemos tirar disso. Alguns artistas e arquitetos citados aqui, podem ser considerados ou ter suas práticas profissionais, consideradas como verdadeiras 'atitudes queer' - visto que colocavam suas ideias e/ ou corpos em oposição as normas em voga - muito antes do termo de fato existir.

Assim, se a teoria crítica avalia o mundo, posso dizer, que a teoria queer questiona a avaliação do mundo. Fundamentada pela teoria feminista e difundida pelas afiliações com a filosofia e a com a sociologia, as teorias queer ${ }^{10}$, desde a década de 1990, discutem 
principalmente sobre as relações de gênero, sexualidade, raça e classe. Aos poucos, os coletivos, artistas e ativistas começaram a organizar-se socialmente e experimentar, transgredir e/ou subverter as tradicionais distinções binárias que organizavam a vida cotidiana e depois o 'assunto' abordado como 'queer' começou a invadir as instituições acadêmicas, partindo principalmente das afiliações com Michel Foucault, Jacques Derrida e mais contemporaneamente Judith Butler.

Antes de virar um termo de 'empoderamento', a palavra queer, dita ou sussurrada como insulto, agora é orgulhosamente, não só proferida, mas também estampada, negociada e comercializada como marca de transgressão por pessoas que antes se chamavam de lésbicas ou gays. Em inglês, o termo tem a função de adjetivo ou verbo e em todos os casos e línguas11 se define em oposição à norma ou a normatização das coisas, das relações, dos espaços. Desse modo, se podemos dizer que a teoria queer é uma escola de pensamento, é importante deixar claro que ela não tem visões ortodoxas de disciplina (cf. SPARGO, 2017). Ela não se impõe como um arcabouço teórico, metodológico ou conceitual, único e sistemático, pelo contrário, se disponibiliza como um acervo de engajamentos intelectuais com as relações de sexo, gênero e desejo sexual em constante trocas com outras disciplinas desestabilizadoras das condições do sujeito. Vem daí a importância da filiação com a obra de Michel Foucault e suas pesquisas sobre o saber e o poder.

O queerness12 na arquitetura tem sido associado à ideia de 'queer spaces' (cf. BETSKY, 1997) - um lugar real, imaginário, projetado (e ocupado) através das políticas de identidade de gênero e sexualidade. Tais conversas - lideradas por Joel Sanders13 e Aaron Betsky14, entre outros - eram ricas, mas relegaram o termo queerness a uma certa parte do processo do design de projeto, privilegiando a política espacial, as

várias vertentes e variedades locais; por isso, atualmente falamos em teorias Queer no plural.

11 Faço essa observação porque na última década a palavra vem ganhando diferentes formas de escrita, como por exemplo "cuir" principalmente em países latinos.

12 O termo não possui uma tradução oficial para o português. Alguns pesquisadores chamariam de "estranheza" já que estranho é a palavra que mais se aproxima do sentido de "queer", mas também usam "singularidade" como sinônimo de queerness. Dentre estas duas opções, me aproximo mais da palavra "estranheza", mas deixo claro que o sentido de queerness aqui, não é uma abordagem estranha do espaço, mas uma atitude de leitura, de olhar para a cidade, paras as relações entre arquitetura e sujeito. Isto é, o queer é uma atitude que se opõe as normas e regras pré-estabelecidas. Sugiro então, que o queerness neste texto seja entendido como uma atitude de apropriação e de subversão dos espaços públicos, assim como suas leituras e significações.

13 Arquiteto norte-americano e professor de arquitetura na Yale Architecture. Seus estudos discutem as 'arquiteturas das masculinidades' e exploraram a complexa relação entre cultura e espaço social, analisando o impacto que as forças culturais em evolução têm sobre o ambiente projetado.

14 Arquiteto norte-americano, diretor da escola de arquitetura e Design no Instituto Politécnico da Universidade de Virgínia. Seus trabalhos discutem principalmente as questões de 'queer spaces'. 
configurações formais e habitações conscientemente abjetas.

As discussões recentes a respeito do assunto revelam novos lugares onde podemos encontrar o queerness especificamente na prática de apropriação dos espaços, não só pela descrição dos usos, mas também por abordar as questões do corpo e da linguagem como categorias analíticas. Isto é, o queerness (ou o queer) é uma atitude que perverte os referentes, que perturba a forma, que subverte as histórias, para flexionar não apenas o que projetamos, mas como projetamos, como pensamos o projeto e como entendemos a cidade e a sociedade.

Pensando em termos de 'queerness', já temos uma geração emergente de artistas, designers, escritores e curadores cujo trabalho demonstra, conscientemente ou não, aproximamentos com a Cultura Queer ${ }^{15}$ extraídas da subversão de regras que regem o comportamento, o vestuário, o sexo, o desejo e a estabilidade corporal: seja por uma dismorfia sutil, seja por brincar com corpos, formas e citações, por um materialismo transgressivo, por uma estética 'camp' e também por uma banalidade crítica.

Desse modo, pensando nesses posicionamentos, estudar a cidade a partir de uma perspectiva queer, certamente contribui com a interdisciplinaridade dos conhecimentos a respeito dos assuntos urbanos. O entendimento da produção espacial urbana e suas relações com os marcadores sociais podem ajudar a entender que o uso/ocupação da cidade são exercícios de cidadania, além de identificar outros sujeitos, proporciona leituras não normativas e diferentes da lógica capitalista.

\section{UMA BREVE IDEIA DA LINGUAGEM COMO PERFORMANCE}

Austin (1990) não foi o primeiro teórico a se preocupar com que a linguagem faz no mundo, mas foi o primeiro a considerar a visão performativa da linguagem (cf. MELO; ROCHA, 2015). O autor desenvolve discussões sobre como agimos no mundo com nossas palavras, ou seja, como a linguagem não só descreve algo, mas também como dá vida sobre o que se fala. Segundo os estudos inicias de Austin, nossos enunciados fazem coisas, isto é, são considerados por ele em relação a sua eficácia em termos de ação no mundo.

Desse modo, segundo a intrigante leitura que Judith Butler faz de Austin, a linguagem tem um potencial tripartido, onde: 1 - existe uma intenção antes do uso da palavra, ou seja, o sujeito é anterior a fala; 2 existe um nível instrumental das palavras; e 3 - um resultado do uso da

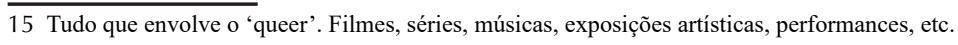


palavra. Assim, para Butler as palavras não são apenas instrumentos para as realizações de ações no mundo, elas são a própria ação (é esse o olhar que colocamos em relação ao 'Queering the Map').

Assim, o que nos interessa observar a partir de agora é, pensando com Butler (1997) como a linguagem faz nascer corpos que ela própria sustenta ou ameaça a existência, ou seja, existimos porque somos reconhecidos pelos outros. Não só por sermos reconhecidos, mas porque temos uma linguagem reconhecível. Portanto, nossas práticas de linguagem são ações que nos constituem, se fazem a partir da repetição, que é sua condição de possibilidade. Desse modo, os nossos discursos têm um papel importante nas nossas vivencias (performances), isto porque nossas palavras, nos colocam no mapa, ela nos faz existir socialmente. Este efeito performativo inaugura e insere novos sentidos subversivos que permitem leituras e interpretações do sujeito, das performances, dos espaços (públicos ou não), portanto, colocam-se como importantes categorias de uma análise que olha para os sujeitos dissidentes.

\section{O SUJEITO-QUEER, UM FLÂNEUR PERVERSO}

Imagem 1 - Interface do site. Foto: Reprodução do site "Queering the Map".

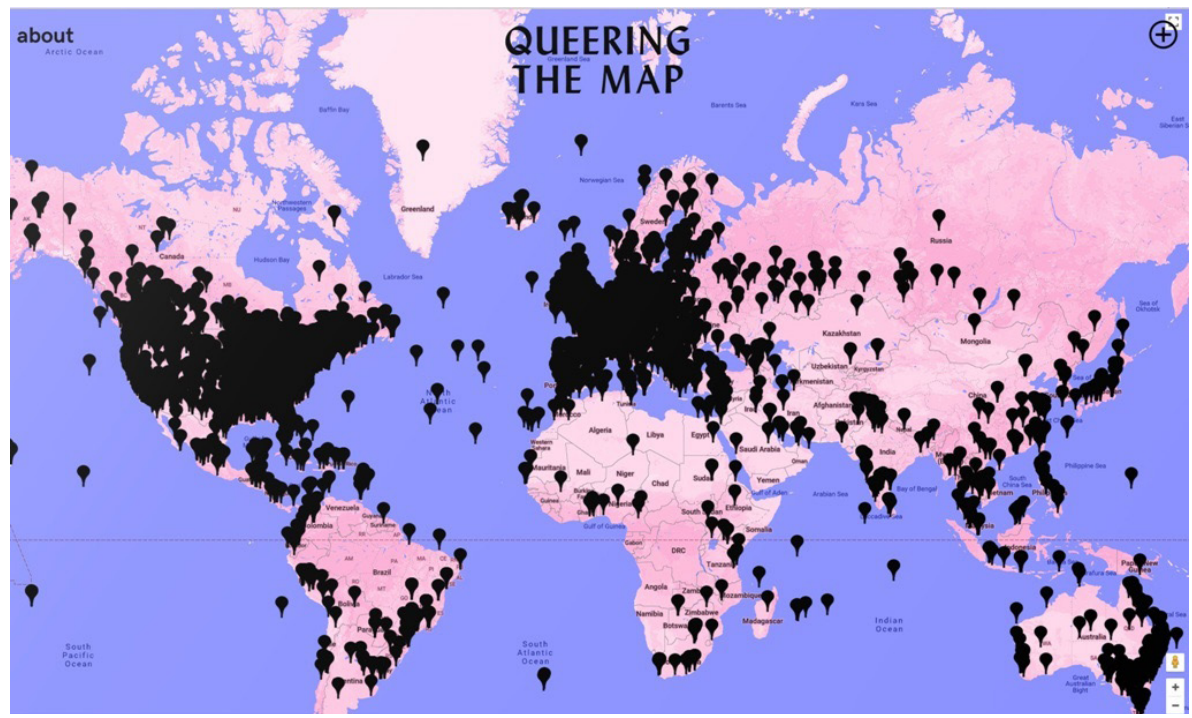


O 'Queering the Map'16 é um projeto do designer canadense Luca LaRochelle $^{17}$, que tem como objetivo mapear de forma colaborativa, isto é, pelas mãos dos próprios habitantes das cidades, as vivências, identidades e momentos relacionados de diversas formas ao termo 'queer'. Descrevendo o projeto de forma bem simples: com a plataforma Maps do Google, o intuito é localizar um lugar no mapa, colocar um marcador e publicar o seu depoimento, anonimamente, sobre uma situação 'queer' relacionada ao espaço (público o privado) em questão. Ação que qualquer pessoa pode fazer.

Em algum ponto do mapa, nos Estados Unidos de Donald Trump, alguém aponta: "Saí do armário aqui, via Instagram, na parada de Nova lorque". No Rio de Janeiro de Witzel e Crivella, alguém crava no mapa: "Beijei uma garota aqui, no banheiro da escola". Outro marcador, na Rocinha diz: "Beijei o meu amor, durante o pôr-do-sol no Rio". No eixo monumental, da desgovernada Brasília as declarações são do tipo "Fodase Bolsonaro" e "Meu primeiro beijo com um menino foi aqui, no beijaço contra um parlamentar homofóbico". São inúmeras as declarações ao redor do mundo que demonstram as afinidades estabelecidas entre identidade, sexualidade, ativismo e espaço público.

A partir das 'declarações queer' de sujeitos anônimos, o mapa que vai sendo construído de maneira colaborativa é marcado por inúmeras lembranças amargas ou doces como essas apresentadas. $\mathrm{O}$ projeto faz uma inusitada cartografia coletiva da cidade nos tempos do GPS, feito em azul e rosa, rosa e azul, quem habita esse mapa é a comunidade LGBTQ+, com todas as suas cores misturadas. O 'queering the map' é mais que um mapa, é um documento de acesso público, é uma ferramenta de inclusão onde todas as histórias são contadas sem protagonistas, ao mesmo tempo que todos são os protagonistas. Além disso, o projeto oferece uma inusitada possibilidade de leitura entre a cidade e as atitudes de apropriação queer, via ciberespaço.

Atualmente, a superfície do projeto está tomada por 'manchas' pretas, tanto são os marcadores acumulados em determinadas áreas (imagem 1). O que nos mostra as áreas de circulação destes corpos, ou seja, por onde as homossexualidades ou as diversas identidades e sexualidades 'queer' estão geograficamente, isto é, é possível ver por

16 Site do projeto: www.queeringthemap.com - Importante dizer que meu interesse aqui, não é analisar os enunciados anônimos deixados na plataforma, mas sim analisar como a plataforma se insere na cartografia e pode ser aproveitada como um dispositivo de análise.

17 Designer canadense, indicado pelo projeto ao Lumen Prize e ao World Design Guide, na categoria de impacto social, em 2018. 
onde estão circulando, imaginar quais percursos e deslocamentos estão fazendo. É muito fácil, pela imagem do projeto, imediatamente relacionar tais manchas as áreas de consumo mais globalizadas, os lugares onde vemos marcações são principalmente nos Estados Unidos e na Europa. Existe uma expressiva quantidade de marcadores em áreas como a Quinta Avenida, em Nova Iorque ou na Avenida Paulista, em São Paulo, em comparação com áreas mais isoladas e/ou interioranas. Isto é, de uma certa forma podemos relacionar que a liberdade indentitária e sexual de um sujeito está geograficamente posta em um circuito que integra vivências com o espaço urbanizado e com o mercado.

Não por acaso, nos últimos anos alguns teóricos queer criticam o fato de que a cultura queer está diretamente associada ao mercado, assim como a sexualidade de uma forma em geral. Você pode assistir um filme queer, uma série queer ou até mesmo usar uma camiseta com a frase 'queer as fuck'. Em outras palavras, é preciso consumir para ser. Assim o 'queer' teria se tornado apenas mais uma categoria identitária, como 'gay' e 'lésbica' (cf. SPARGO, 2017). Existem até mesmo bairros completamente dedicados a cultura queer, como o Castro, em São Francisco, na Califórnia. Considerado um bairro "descolado" com as faixas de pedestres nas cores do arco-íris e praças públicas reservadas para discutir e lembrar o ativismo. Castro, é o exemplo físico daquilo que configura o tecido urbano: o consumo e a circulação das pessoas, mas o queer não é só isso.

Há cem anos, obviamente, já existiam gays passeando por São Paulo, mas não haviam boates ou bares dedicados exclusivamente para este público. A "comunidade" da época frequentava lugares onde todo mundo ia: cabaré, restaurantes, cafés, teatros e tudo junto e misturado, inclusive com preconceito e homofobia. Os gays na época eram chamados de "frescos" ou "pederastas" e considerados figuras folclóricas e marginais (cf. TREVISAN, 2018) sempre ligados a um submundo muito próximo das prostitutas, cafetinas, michês, malandros e contraventores de modo geral. Mesmo assim, havia para os devassos da época, um espaço relativamente livre: a rua.

Atualmente, no mundo globalizado que vivemos, temos a sensação de liberdade e de livre circulação, o que não é totalmente verdade. Nesse sentido o 'queering the map' coloca em exposição os lugares da cidade onde os corpos queer estão, as palavras contam as experiências de indivíduos que vivem, convivem e sentem os espaços urbanos de maneiras muito particulares. Desse modo, o mapa se coloca como um 
dispositivo marcador e de visualização da circulação dos afetos e dos sujeitos-queer na cidade, já que os marcadores estão alinhados com a questão afetiva, sentida naquele momento ${ }^{18}$. Os sujeitos ao circularem pela cidade, surgem então, como uma figura de flâneur perverso, isto é, um explorador urbano que passeia pela cidade em busca de novidades e acontecimentos.

Desse modo, a plataforma fornece novos caminhos para se pensar as relações estabelecidas na cidade. Ela é capaz de registrar os movimentos das diferentes identidades sexuais e dos usos dos espaços e das práticas urbanas que emanam a partir da circulação desse sujeitoqueer, o flâneur moderno. Este 'mapa humano' expõe através dos enunciados anônimos o que as vezes é difícil de explicar: as relações entre espaço, gênero, sexualidade, afetividade, etc. A ferramenta mescla o corpo, o espaço e a língua, assim, as palavras atreladas à um espaço físico, formam o dispositivo cartográfico de análise, já que elas estão narrando as experiências e os modos de produção da subjetividade dos sujeitos-queer. É, de fato, a linguagem como performance.

\section{CONSIDERAÇÕES PROVISÓRIAS}

É claro que os questionamentos em relação a ocupação humana do espaço público sempre existiram. Posso dizer que as aproximações entre a Arquitetura e o Queer aconteceram inicialmente a partir de uma abertura fenomenológica aos novos discursos e modos de análises sociais urbanas, principalmente a partir das observações postas pelo Movimento Feminista. Na história recente, essa aproximação, acontece muito antes do 'queer' de fato existir, como pude demonstrar no início desta conversa. Desde os anos 1930, mas principalmente a partir dos anos 1960, as discussões sobre as apropriações cotidianas dos espaços foram fomentadas não só por arquitetos, mas também por diversos artistas, ativistas e coletivos. Falar sobre identidade, sobre sexualidade é falar sobre a vida social, portanto são assuntos indissociáveis das análises sociais urbanas.

Ao olhar para o 'Queering the Map' como uma ferramenta de observação do sujeito-queer - que se insere nessa discussão como uma espécie de flâneur perverso - podemos observar como o sujeito é um produto de um momento sócio histórico. Ele é sempre produzido e

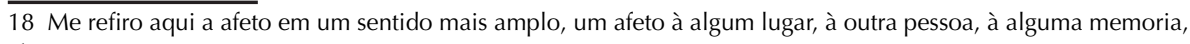
etc. 
regrado pela ordem social que organiza as experiências dos indivíduos em um determinado momento. Todo corpo é potencialmente desviado, considerado como um indivíduo que deve ser corrigido e, por isso, deve circular por um conjunto de arquiteturas políticas e controladoras que vão garantir a sua normatização (a casa, a escola, o quartel, o hospital etc.). Por isso, mesmo as declarações anônimas do projeto, se inserem como um grito de representação no espaço público das cidades. Os relatos estão dizendo 'estamos aqui, ocupamos o espaço e somos queers e daí?'. Essas palavras fazem emergir do mapa o ethos ativista de um sujeito que luta pelos seus direitos de ocupar e viver os espaços urbanos, assim como todos os cidadãos.

A breve análise apresentada nos permite dizer que o sujeito está diretamente ligado ao espaço urbano e ao consumo, o que torna esse sujeito, um sujeito social. Assim, considerar os marcadores sociais (gênero, sexo, raça e classe) como categorias de análise se faz fundamental para uma leitura diferenciada dos padrões normativos existentes em nossa sociedade. Considerá-los é, portanto, inseri-los no mapa. Mesmo de forma anônima, os enunciados dão visibilidade aos corpos dissidentes no espaço urbano, isto é, são intervenções com o discurso no território, pelo ciberespaço. Dessa forma, posso dizer que traçar uma cartografia a partir desse dispositivo requer enfatizar como o discurso e a representação, constrói um sujeito que é possível de explicar e descrever. Isto é, a linguagem não é uma mera forma de comunicação, pelo contrário, nossas palavras são ações que ratificam pensamentos, posições, desejos etc. As palavras trazem à existência aquilo sobre o que se fala.

\section{REFERÊNCIAS}

AUSTIN, J. L. Quando dizer é fazer. Palavras e ação. Trad. de MARCONDES, D. Porto Alegre: Artes Médicas: 1990.

BARONE, A. Team 10: arquitetura como crítica. São Paulo, Annablume: Fapesp. 2002.

BETSKY, A. Queer Space: Architecture and Same Sex Desire. Nova lorque: William Morrow and Company, 1997.

Building Sex: Men, Women, Architecture and the Construction of Sexuality. Nova York: William Morrow and Company, 1995.

BOUTINET, J. Antropologia do Projecto. Lisboa, Instituto Piaget. 1990. 
BUTLER, J. Problemas de gênero. Feminismo e subversão da identidade. $14^{\mathrm{a}} \mathrm{ed}$. Rio de Janeiro: Civilização brasileira, 2017.

. Excitable speech: a politics of the performative. New York: Routledge, 1997.

CORTÉS, J.M.G. Políticas do espaço: arquitetura, gênero e controle social. Tradução de Silvana Cobucci Leite. São Paulo: Editora Senac São Paulo, 2008.

DEBORD, G. Introducción a uma crítica de la geografia urbana. In: ANDREOTTI, L. \& COSTA, X. (org.) Teoria de la deriva y otros textos situacionistas sobre la ciudad. Barcelona: Actar, 1996.

FOUCAULT, M. Vigiar e punir: nascimento da prisão. Petrópolis, Vozes. 1987.

GEHL, J. Cidades para pessoas. Tradução, Anita Di Marco. 3 ed. São Paulo: Perspectiva, 2015.

LEFEBVRE, H. O direito à cidade. Tradução Rubens Eduardo Frias. São Paulo: Centauro, 2001.

MAINGUENEAU, D. Gênese dos discursos. São Paulo: Parábola, 2008.

MELO, G. V.; ROCHA, L. L. Linguagem como performance: Discursos que também ferem. In: Discurso: sentidos e ação. Marilia Giselda Rodrigues et al., organizadoras. Franca, SP: Universidade de Franca, 2015.

NESBITT, K (Org.). Uma nova agenda para a arquitetura: antologia teórica (1965 - 1995). Tradução: Vera Pereira. São Paulo: Cosac Naify, 2006.

PRECIADO, P. B. “Cartografias 'Queer': O 'Flâneur' Perverso, A Lésbica Topofóbica e A Puta Multicartográfica, Ou Como Fazer uma Cartografia 'Zorra' com Annie Sprinkle". eRevista Performatus, Inhumas, ano 5, n. 17, jan. 2017. ISSN: 2316-8102.

SENNETT, R. Carne e pedra: o corpo e a cidade na civilização ocidental. Tradução de Marcos Aarão Reis. 4 ed. Rio de Janeiro: Best Bolso, 2016.

SPARGO. T. Foucault e a teoria queer. Belo Horizonte: Autêntica, 2017.

TREVISAM, J. S. Devassos no Paraíso: a homossexualidade no Brasil, da colônia à atualidade. 4 ed. rev., atual. e amp.. - Rio de Janeiro: Objetiva, 2018.

VILLAÇA, N. Os imagineiros do contemporâneo: representações e simulações. In: VELLOSO, M. P.; ROUCHOU, J.; OLIVEIRA, C. (Orgs.). Corpo: identidades, memórias e subjetividades. Rio de Janeiro: Mauad X/ FAPERJ, 2009.

Recebido em: 16/07/2020

Aceite em: 01/12/2020 